\title{
Democracia e Estado de Direito no Brasil O Problema da Inefetividade dos Direitos Fundamentais no País
}

\author{
Laís Marcelle Nicolau Abrantes \\ Mestre em Direitos Humanos pelo Programa de Pós- \\ -Graduação em Ciências Jurídicas da UFPB. Especialista \\ em Direito Constitucional pelo Unipê. Bacharel em Direito \\ pela UFPB. Professora efetiva do IFPB. laismarcelle@hot- \\ mail.com
}

\begin{abstract}
Resumo
0 presente artigo trata, a partir da análise da relação existente entre democracia e Estado de Direito, da problemática da inefetividade dos direitos fundamentais no Brasil e suas repercussões para 0 sistema político do país. Nesse sentido, para a abordagem da temática proposta, é tomado como referencial teórico o conceito procedural mínimo de democracia elaborado por Scott Mainwaring, Daniel Brinks e Aníbal Pérez-Liñán. Partindo desse conceito, o artigo examina, mediante revisão bibliográfica e documenttal, o desenvolvimento da democracia no Brasil e, em ato contínuo, discorre sobre as fases do Estado de Direito brasileiro, dando ênfase à fase atual, isto é, ao proclamado Estado Democrático de Direito. Por fim, é posta em evidência a inefetividade de muitos direitos fundamentais constitucionalmente assegurados no país, ressaltando-se, por conseguinte, as consequências advindas dessa realidade.
\end{abstract}

Palavras-chave: Democracia. Estado de Direito brasileiro. Inefetividade dos direitos fundamentais. 


\title{
Democracy And Rule of Law In Brazil: \\ The Issue Of Fundamental Rights' Ineffectiveness In The Country
}

\begin{abstract}
This article deals, coming from the analysis of the relationship between democracy and Rule of Law, with the issue of fundamental rights' ineffectiveness in Brazil and its impact on the country's political system. In this sense, to approach the proposed theme, it is taken as the theoretical referential the minimum procedural concept of democracy prepared by Scott Mainwaring, Daniel Brinks and Aníbal Pérez-Liñán. Based on this concept, the article examines, by bibliographic and documentary review, the development of democracy in Brazil and, immediately thereafter, discusses the phases of the Brazilian Rule of Law, emphasizing the current phase, ie, the proclaimed Democratic Rule of Law. Finally, it also highlights the ineffectiveness of many fundamental rights constitutionally guaranteed in the country, stressing, therefore, the consequences arising from this reality.
\end{abstract}

Keywords: Democracy. Brazilian Rule of Law. Ineffectiveness of fundamental rights.

Sumário: 1 Introdução. 2 Democracia e seus conceitos. 3 Breves considerações sobre o desenvolvimento da democracia no Brasil. 40 Estado de Direito brasileiro. $4.1 \mathrm{~A}$ inefetividade dos direitos fundamentais no Brasil. 5 Considerações Finais. 6 Referências. 


\section{INTRODUÇÃO}

No panorama internacional contemporâneo, constata-se que a maior parte dos países no mundo deseja ser contemplada como democrática. De fato, em um contexto internacional cujo fundamento basilar constitui a proteção da dignidade humana e dos direitos humanos, não existe qualquer espaço para o desenvolvimento de regimes que não primem pelo exercício democrático do poder.

Ocorre que, embora a ideia de democracia que se tem hoje possua suas raízes nas teorias clássicas da Modernidade, uma vez que se encontra centrada na perspectiva representativa do regime, ela não traduz um pensamento uníssono. Pelo contrário, no que diz respeito ao conceito que recai sobre a definição do regime político democrático, muitas divergências são produzidas.

Nesse ponto, o presente artigo parte de sucinta abordagem das principais teorias procedurais atuais da democracia, isto é, a teoria representada pelo pensamento de Joseph A. Schumpeter e a representada pelas proposições de Scott Mainwaring, Daniel Brinks e Aníbal Pérez-Liñán, detendo-se ao conceito democrático mínimo proposto por esses últimos autores. Tal conceito leva em conta não apenas a dimensão eleitoral do regime, mas também outras dimensões consideradas igualmente importantes e que conduzem à conclusão de que a autêntica existência de uma democracia exige, necessariamente, o funcionamento de um Estado de Direito.

Nessa perspectiva, busca-se, mediante apurada revisão bibliográfica e documental, abordar o desenvolvimento da democracia no Brasil bem como as diversas fases do Estado de Direito vividas no país. Finalmente, sob o referido pano de fundo, procura-se discorrer sobre os elementos do Estado de Direito brasileiro atual e sobre a inequívoca problemática da inefetividade dos direitos fundamentais no Brasil. 


\section{DEMOCRACIA E SEUS CONCEITOS}

Considerando o contexto político global atual, pode-se afirmar que a maior parte dos países hoje se autointitula democrática. Isto porque, após a Segunda Guerra mundial (1939-1945), houve mobilização internacional em prol da manutenção da paz entre os países, com o fundamento basilar da internacionalização do respeito à dignidade humana e da proteção dos então denominados direitos humanos. Assim, passou a não haver mais espaço, no plano das relações internacionais, para regimes autoritários e violadores dos novos patamares jurídicos postos.

Com efeito, após a Segunda Guerra, tornou-se meta internacional construir um aparato jurídico que estivesse voltado à proteção dos direitos humanos e que envolvesse todos os países do mundo. Em consequência disso, foi criada, em 1945, a Organização das Nações Unidas (ONU) e proclamada, em 1948, a Declaração Universal dos Direitos Humanos. Tais fatos deram início a uma nova ordem jurídica internacional, na qual a democracia passou a ser vista como o regime político capaz de viabilizá-la.

Por essa razão, os países se esforçam para ser associados a regimes democráticos, mascarando, muitas vezes, características suas que jamais poderiam ser consideradas, de fato, democráticas. Por conseguinte, vê-se que o termo democracia alçou inequívoca conotação positiva no mundo contemporâneo, de modo que, nas palavras de Bobbio (1991, p. 43), “[...] não há regime, mesmo o mais autocrático, que não deseje fazer-se conhecer como democrático".

Convém ressaltar, entretanto, que a democracia nem sempre foi vista na história da humanidade como o melhor regime político. $\mathrm{Na}$ verdade, a própria ideia que se tem atualmente acerca da democracia enquanto regime representativo, ideia esta surgida na Modernidade, não é a mesma que se tinha na Antiguidade, quando a conotação a ela atribu- 
ída era claramente negativa. Para os antigos, a democracia era concebida enquanto democracia direta, como bem-expõe Bobbio (1991, p. 40) na seguinte passagem:

Para os antigos, a imagem da democracia era completamente distinta. Quando falavam em "democracia" pensavam numa praça, ou assembleia, em que cidadãos eram convocados a tomar, eles próprios, as decisões de governo. Este era o significado literal da palavra: o poder do demos, não o poder dos representantes do demos, como acontece hoje.

Na Antiguidade, a democracia era um regime bastante questionável, porquanto conferia ao povo a responsabilidade de tomar diretamente as necessárias decisões políticas. Nesse sentido, apontava-se que conferir ao povo a soberania para a tomada de tais decisões era algo irrazoável, uma vez que ele era considerado fraco e dominável por paixões (p. 26).

De qualquer forma, após o advento das revoluções burguesas e o fim do Estado Absolutista, contribuições de filósofos como Montesquieu e Rousseau forjaram as bases da ideia de democracia representativa que se tem hoje, à qual se atribui sentido político extremamente positivo.

É bem verdade que a teoria clássica da democracia se distingue da teoria atual, uma vez que se atém à realização do bem comum e da vontade do povo, considerados por muitos hoje, empiricamente inalcançáveis. A grande discussão que se estabelece no panorama contemporâneo global, e dentro da perspectiva representativa da democracia, no entanto, não consiste na crítica à teoria clássica, mas no debate acerca do conceito que, de fato, define o regime político democrático.

Nessa direção, pode-se afirmar que duas teorias se destacam no que diz respeito à definição da democracia sob uma perspectiva empírica. A primeira teoria é a representada principalmente pelo pensamento de Joseph A. Schumpeter, o qual pretendeu, com seus escritos, elaborar uma definição procedural mínima de democracia. 
Nesse sentido, pode-se afirmar que o autor, ao tratar da questão democrática, enaltece, desde lodo, o modo de escolha dos governantes, destacando que “[...] o método democrático é um sistema institucional, para tomada de decisões políticas, no qual o indivíduo adquire o poder de decidir mediante uma luta competitiva pelos votos do eleitor" (SCHUMPETER, 1961, p. 328). Mais adiante, o autor detalha que:

[...] de acordo com o ponto de vista que adotamos, a democracia não significa nem pode significar que o povo realmente governa em qualquer dos sentidos tradicionais das palavras povo e governo. A democracia significa apenas que o povo tem oportunidade de aceitar ou recusar aqueles que o governarão (p. 346).

Percebe-se, então, que essa teoria se atém à questão eleitoral para definir minimamente a democracia, enfatizando a oportunidade de escolha que tem o eleitorado e o exercício do poder pelo indivíduo por meio da competição pelos votos do eleitor. Por esse motivo, ela é conhecida como teoria competitiva da democracia. A respeito dela, Albuquerque (2009, p. 135) preconiza que:

Assim, para Schumpeter, a democracia é um método de escolha daqueles que irão governar, no qual políticos profissionais disputam em um processo de livre concorrência os votos do eleitorado. Para ele a democracia é o governo dos políticos. Visto desta forma, esta concepção passou a denominar-se teoria competitiva da democracia.

$\mathrm{Na}$ mesma linha de raciocínio e, portanto, dentro dessa teoria, destacam-se as contribuições de outros autores relevantes, a exemplo de Robert A. Dahl e Samuel P. Huntington. O pensamento de Dahl tem a peculiaridade de realizar, inicialmente, a distinção entre democracia ideal e democracia real, isto é, entre a democracia desejada e a democracia empiricamente possível, a qual denominou poliarquia. 
Partindo desse pressuposto, Dahl retrata, com bastante ênfase, quais instituições políticas são necessárias à constituição de uma poliarquia, configurando-se elas, para ele, as exigências mínimas para que um país possa ser considerado democrático. Nesse sentido, lista as seguintes instituições: funcionários eleitos; eleições livres, justas e frequentes; liberdade de expressão; fontes de informação diversificadas; autonomia para as associações; e cidadania inclusiva (DAHL, 2001, p. 99).

Pode parecer, em uma primeira leitura de tais instituições, que Dahl vai além da estrita dimensão política argumentada por Schumpeter acerca da democracia, pois, entre elas, lista-se a cidadania inclusiva. Ao discorrer sobre essa cidadania, no entanto, o referido autor se limita a atrelá-la ao exercício de direitos relacionados às demais instituições políticas retratadas. Segundo ele:

Cidadania Inclusiva. A nenhum adulto com residência permanente no país e sujeito a suas leis podem ser negados os direitos disponíveis para os outros e necessários às cinco instituições políticas anteriormente listadas. Entre esses direitos, estão o direito de votar para a escolha dos funcionários em eleições livres e justas; de se candidatar para os postos eletivos, de livre expressão, de formar e participar de organizações independentes; de ter acesso a fontes de informação independentes; $\mathrm{e}$ de ter direitos a outras liberdades e oportunidades que sejam necessárias ao bom funcionamento das instituições políticas da democracia [...]. (DAHL, p. 100).

Assim, é possível perceber que os direitos defendidos por Dahl na sustentada cidadania inclusiva se restringem apenas aos direitos políticos. Embora, portanto, possua características particulares, a teoria democrática de Dahl não foge à linha defendida por Schumpeter, pois mantém seu conceito procedural mínimo de democracia dentro da esfera política. 
Da mesma forma que Dahl, Huntignton também segue o pensamento de Schumpeter em termos democráticos. De fato, em sua definição procedural de democracia, Huntignton (1993, p. 7) afirma, de maneira categórica, em sua obra The Third Wave, que:

Seguindo na tradição Schumpteriana, este estudo define um sistema político do século XX como democracia a extensão onde os representantes responsáveis pelas mais poderosas decisões coletivas são escolhidos mediante eleições justas, honestas e periódicas, nas quais os candidatos competem livremente pelos votos e toda população adulta é considerada elegível (Tradução nossa). ${ }^{1}$

Na visão do referido autor, não há espaço para concepções normativas de democracia em sua definição mínima. Logo, para ele, não importa se os governos eleitos são ineficientes, corruptos ou irresponsáveis. O traço mínimo que distingue um regime democrático dos demais reside na existência de eleições justas, honestas e periódicas (1993, p. 10). Para Huntignton (1993, p. 9),

[...] a definição de democracia em termos de eleições é uma definição mínima. Para algumas pessoas a democracia tem ou deveria ter conotações muito mais abrangentes e idealistas. Para eles, a "verdadeira democracia” significa liberté, égalité, fraternité, um controle efetivo dos cidadãos sobre a política, governo responsável, honestidade e abertura na política, deliberações racionais e fundadas em informações, igualdade na participação e no poder, e várias outras virtudes cívicas. [...] Eleições igualitárias, livres e justas são, entretanto, a essência da democracia, sua inescapável condição sine qua non (Tradução nossa). ${ }^{2}$

${ }^{1}$ Following in the Shumpeterian tradition, this study defines a twentieth-century political system as democratic the extent that its most powerful collective decision makers are selected trough fair, honest, and periodic elections in which candidates freely compete for votes and in which virtually all the adult population is eligible to vote.

2 [...] the definition of democracy in terms of elections is a minimal definition. To some people democracy has or should have much more sweeping and idealistic connotations. To them, "true democracy" means liberté, egalité, fraternité, effective citizen control 
Apesar da linha de raciocínio desses três autores mencionados ser bastante conhecida e ter consideráveis repercussões no âmbito do debate tratado, outra forma de pensamento se destaca no emblema da conceituação da democracia. Esse pensamento é justamente o representado pelas proposições postas por Scott Mainwaring, Daniel Brinks e Aníbal Perez-Liñán na obra "Classificando regimes políticos na América Latina, 19451999" (2001).

Nessa obra, os autores fazem uma crítica à concepção democrática de Schumpeter e seus seguidores, denominando-a submínima. Para Mainwaring, Brinks e Perez-Liñán (2001, p. 141), não obstante a democracia deva ser contemplada como um procedimento que utiliza eleições livres e justas para a escolha dos representantes políticos, sua definição não pode se limitar a essa dimensão eleitoral, considerada, portanto, como insuficiente.

Desse modo, os referidos autores encaram a definição de Schumpeter como submínima, ao passo que se propõem a definir uma concepção procedural mínima de democracia. Para tanto, Mainwaring, Brinks e Perez-Liñán (2001, p. 141) afirmam, inicialmente, que “[...] não é possível considerar o caráter meramente eleitoral da democracia, deixando de lado aspectos igualmente importantes e correlatos a essa primeira dimensão”.

Assim, para compreender minimamente a democracia, conforme essa maneira de pensar, faz-se necessário considerar quatro importantes dimensões democráticas. A primeira consiste na exigência de eleições competitivas, livre e justas para os representantes do Legislativo e Executivo; a segunda implica garantia de uma cidadania adulta e abrangente; a terceira consiste na necessidade de proteção das liberdades civis e dos

over policy, responsible government, honesty, equal participation and power, and various other civic virtues. [...] Elections, open, free, and fair, are the essence of democracy, the inescapable sine qua non. 
direitos políticos; e a quarta refere-se à existência de poder genuíno das autoridades para governar (2001, p. 648-651). A respeito dessas dimensões, Mainwaring, Brinks e Perez-Liñán (2001, p. 651) prelecionam que:

Todas as quatro dimensões de nossa definição são necessárias e devem ser incluídas mesmo que isto exija fazer julgamentos subjetivos sobre os regimes. Essa definição atende ao duplo requisito de ser mínima e completa, quando: a) todos os quatro critérios são componentes necessários da democracia, sem os quais um regime não pode ser considerado democrático; b) nenhum outro aspecto, além desse, é indispensável para caracterizar uma democracia. Acreditamos que nossa definição satisfaz às duas condições, enquanto algumas definições recentes falham na segunda delas porque negligenciam certas características essenciais da democracia.

Nesse sentido, considerando o conceito mínimo de democracia posto por Mainwarign, Brinks e Perez-Liñán, vemos que uma definição adequada e realística de democracia envolve necessariamente características que vão muito mais além da mera dimensão eleitoral. É bem verdade que essa dimensão é fundamental, porém ela não deve ser encarada como a única dimensão necessária para a conceituação do que significa um regime democrático.

Assim, tendo o devido respeito à importância das contribuições feitas por Schumpeter e demais autores subminimalistas, a concepção mínima de democracia, embora não esteja alheia a críticas e eventuais acréscimos, parece ser bem mais completa e aplicável diante do contexto político e jurídico contemporâneo.

Ao tratar de outras dimensões essenciais ao conceito procedural de democracia, a concepção mínima traz à tona aspectos importantes a serem considerados e discutidos. Assim, levando em conta a temática em análise, cabe destacar a relevante contribuição de tal concepção ao inserir, diante 
da afirmação de que as liberdades civis e os direitos políticos constituem características essenciais a um regime democrático, a existência de um Estado de Direito na definição de democracia.

De fato, sem o devido respeito às liberdades civis e aos direitos políticos, não se pode reconhecer, ao contrário do que afirmam os positivistas, a existência de um autêntico Estado de Direito. Logo, sua presença é indispensável em um regime democrático. Nas palavras dos próprios autores tratados, "em uma democracia, violações aos direitos humanos não são comuns, os partidos são livres para se organizar e o governo respeita as garantias constitucionais” (2001, p. 659).

\section{BREVES CONSIDERAÇÕES SOBRE O DESENVOLVIMENTO DA DEMOCRACIA NO BRASIL}

Partindo do conceito procedural mínimo de democracia definido pelos autores Mainwaring, Brinks e Perez-Liñán, na obra "Classificando regimes políticos na América Latina, 1945-1999” (2001), que considera quatro dimensões essenciais a um regime democrático, pode-se afirmar que o processo de democratização do Brasil percorreu um longo e árduo caminho.

Ainda no Império, alguns mecanismos ligados à ideia democrática foram instituídos. A Constituição de 1824, primeira após a proclamação da Independência (1822), estabeleceu no país os três poderes tradicionais do Estado Moderno: o Legislativo, o Executivo e o Judiciário. Instituiu também um poder adicional, denominado Moderador, o qual recaía exclusivamente sobre a figura do imperador.

Durante esse período, o direito ao voto para compor o Poder Legislativo do país foi respeitado, mas seu exercício restringia-se à população masculina adulta e estava diretamente relacionado à renda mínima de 
cada homem. Além disso, em razão da intensa luta política da época, as eleições eram frequentemente fraudadas, cheias de tumulto e violência (CARVALHO, 2006, p. 33).

Tal fato demonstra que havia clara ausência de voto livre e igualitário e de eleições lícitas e competitivas. Essa ausência, somada à realidade de uma cidadania exclusivista e precária em relação não apenas aos direitos políticos, mas também aos civis e sociais, constata a inexistência de uma democracia no Brasil durante essa época.

Após o fim da escravidão (1988) e o advento do período Republicano (1989), alguns avanços foram conquistados, a exemplo da concessão da cidadania aos que eram escravos. As expectativas, porém, não corresponderam à realidade, tal como retrata Carvalho (2006, p. 40) no seguinte trecho:

A República, de acordo com seus propagandistas, sobretudo aqueles que se inspiravam nos ideais da Revolução Francesa, deveria representar a instauração do governo do país pelo povo, por seus cidadãos, sem a interferência dos privilégios monárquicos. No entanto, apesar das expectativas levantadas [...], pouca coisa mudou com o novo regime.

A Constituição de 1891 não estendeu o direito ao voto a toda população; pelo contrário, manteve excluídos do seu exercício os analfabetos, as mulheres, os mendigos, os soldados e os membros das ordens religiosas. Em termos de proteção de direitos, um tímido avanço foi conquistado, mas muitas leis permaneceram apenas no papel, impedindo que a cidadania fosse vivida na prática por todas as pessoas, inclusive pelos ex-escravos.

Foi apenas com a Revolução de $30^{3}$ que houve considerável avanço democrático no país. A partir de então foram realizadas eleições competitivas e foi promovida a ampliação dos direitos dos cidadãos, o que acarretou

${ }^{3}$ Segundo Carvalho (2006, p. 89): "Em 3 de outubro de 1930, o presidente da República, Washington Luís, foi deposto por um movimento armado dirigido por civis e militares [...]. O episódio ficou conhecido como a Revolução de 30 [...]”. 
o consequente avanço da cidadania no país. Embora esse avanço tenha sido conturbado pelo golpe de Getúlio Vargas em 1937 e pelos efeitos do seu populismo, foi retomado e ampliado a partir da derrubada de Vargas em 1945.

Não obstante, todavia, o período entre 1930 e 1937 tenha representado considerável evolução do Brasil em termos democráticos, o período entre 1945 e 1964 é reconhecido, no contexto do processo de democratização do país, como a primeira experiência realmente democrática de sua história (2006, p. 127). Durante esses anos, foram realizadas eleições regulares para presidente da República e demais cargos oriundos do Poder Legislativo. Ademais, a Constituição de 1946 assegurou tanto direitos civis e políticos quanto também sociais.

Ocorre que, em 1964, o desenvolvimento democrático do Estado brasileiro esbarrou em um duro golpe militar, cujo regime ditatorial, então instaurado, perdurou até o ano de 1985. Durante esses anos sombrios da História do Brasil, houve intensa repressão política e violenta restrição de direitos civis e políticos (2006, p. 157-158). A democracia sumiu e o país deu muitos passos para trás.

Apesar do retrocesso, durante o período da ditadura, principalmente a partir da década de 70, houve muitas manifestações populares contra o regime e seus abusos. No início da década de 80 começou a tomar forma no país o movimento popular das Diretas Já, que lutou pela instituição de eleições diretas e que eclodiu nas ruas no ano de 1984 (PAIXÃO, 2011, p. 14-17).

Foi, então, dado início ao processo de redemocratização do Brasil, que teve como marco histórico de sua consolidação a promulgação da Constituição Federal de 1988. Essa Carta, redigida e aprovada por uma Constituinte adequadamente estabelecida, possui o texto mais liberal e democrático que o país já teve, razão pela qual é amplamente conhecida como “Constituição Cidadã”. 
A partir dela, o direito ao voto foi estendido e tornado obrigatório a todas as pessoas maiores de 18 anos. Aos maiores de 16 anos, o direito ao voto foi tornado facultativo, assim como foi feito em relação aos analfabetos, o que representou, conforme retrata Carvalho (2006, p. 200), a eliminação do “[...] grande obstáculo ainda existente à universalidade do voto”. Ademais, convém destacar que a Carta de 1988 foi além ao consagrar, em seu artigo 60, o direito ao voto como cláusula pétrea constitucional. ${ }^{4}$

Nessa mesma perspectiva, a Constituição assegurou e ampliou em seu texto o exercício de direitos políticos e de direitos civis, tão violados no período da ditadura. Esses direitos, juntamente com os direitos sociais, foram reconhecidos como fundamentais a todo ser humano, razão pela qual foram abordados em título próprio do texto constitucional.

A garantia desses direitos a todas as pessoas na sociedade, contempladas por meio do princípio da igualdade de todos perante a lei, demonstra que uma das características da redemocratização do Brasil é justamente o objetivo de assegurar o exercício da cidadania por todos. Inclusive, foram ampliados pelo texto constitucional, com o intuito de envolver mais o povo no exercício democrático do poder, os mecanismos que viabilizam a participação popular direta em decisões políticas.

No tocante ao exercício do poder pelos representantes eleitos pelo povo, uma vez que o regime democrático atual é, em essência, o representativo, pode-se afirmar que não há empecilhos que obstem o exercício desse poder. Os militares não mais dirigem as decisões políticas do país. As únicas direções que existem no exercício do poder no Brasil, o qual permanece estruturado na moderna repartição de funções do Estado, são as do sistema de freios e contrapesos entre essas funções e de leis que permitem a fiscalização dos atos políticos pela população do país.

${ }^{4}$ Constituição Federal, artigo $60, \S 4^{\circ}$. Não será objeto de deliberação a proposta de emenda tendente a abolir: [...] II - o voto direto, secreto, universal periódico [...]. 
Assim, a partir dessas breves considerações, é possível perceber que o desenvolvimento da democracia no Brasil constituiu processo bastante complexo, permeado por fases diversas e problemas desafiadores. Apesar do avanço do país no tocante às quatro dimensões essenciais à democracia retratadas por Mainwaring, Brinks e Perez-Liñán (2001, p. 648-651), entretanto, não se pode afirmar que esse processo tenha sido concluído. A verdade é que o país ainda passa por sérios problemas que demonstram reais falhas na estrutura e funcionamento de sua democracia, evidenciando que ela ainda possui um longo caminho a percorrer.

\section{O ESTADO DE DIREITO BRASILEIRO}

A expressão lexical "Estado de Direito" foi utilizada pela primeira vez por J. W. Placidus, em meados de 1798, na Alemanha (COSTA, 2006, p. 112). Essa expressão passou a resumir o fenômeno político e jurídico vivido na Europa após o advento das revoluções burguesas e da consequente queda do Absolutismo estatal durante o final do século 18.

Tal fenômeno caracterizou-se, em particular, pelo fim dos privilégios oriundos do Estado absolutista e pelo estabelecimento de limites legais ao exercício do poder estatal. Por conseguinte, a partir desse período, foi assimilada a compreensão da necessidade de se instituir um ordenamento jurídico pautado na repartição das funções estatais e na garantia igualitária dos direitos do homem.

Desse modo, a lei deixou de ser aquilo que o soberano instituía de maneira arbitrária, passando a assumir o importante papel de assegurar o exercício da cidadania a todas as pessoas. Ademais, a titularidade do poder no Estado foi atribuída ao próprio povo, razão pela qual não restou mais espaço, nos planos político e jurídico, para tratamentos distintamente 
privilegiados. Com o tempo, esse modelo político alcançou a maior parte dos países ocidentais, fazendo nascer, assim, as bases conceituais do que hoje se compreende por Estado de Direito.

Na verdade, quando essa expressão surgiu, sua utilização restringia-se aos limites circunstâncias do contexto histórico relativo ao século 18. Nos dias atuais, entretanto, vê-se que "Estado de Direito" expressa não apenas o novo formato de Estado adotado durante a Modernidade, mas também o Estado contemplado sob o ponto de vista contemporâneo, o qual possui suas raízes no Estado de Direito moderno, mas que se caracteriza também por alterações sofridas durante o curso da História.

Em termos doutrinários, existem algumas divergências no tocante à definição da referida expressão. Pode-se afirmar, contudo, que a maior parte dos autores converge sua maneira de pensar ao posicionamento de Borda (2007, p. 73-74), que, ao tratar do assunto, afirma que:

\begin{abstract}
A ideia básica do conceito de Estado de Direito consiste em que sua tarefa é assegurar a liberdade e a propriedade do cidadão e seu objeto é a promulgação do bem-estar do indivíduo e, dessa maneira, conformar seu caráter de "ente comum". [...] Trata-se de uma ordem estatal expressada através de uma constituição escrita, do reconhecimento dos direitos do homem, da separação de poderes e da garantia de leis produzidas e promulgadas conforme procedimentos devidamente estabelecidos (Tradução nossa)..$^{5}$
\end{abstract}

Nesse sentido, percebe-se que o conceito de Estado de Direito relaciona-se à relação estabelecida entre indivíduo, direito e poder. Desse modo, considerando que essa relação passa por inevitáveis mudanças em

\footnotetext{
${ }^{5}$ La idea básica de este concepto de Estado de derecho consiste en que su tarea es el aseguramiento de la libertad y propriedad del ciudadano, su objeto la promoción del bienestar del individuo y, de esa maneira, conformar su caracter como "ente común". [...] Se trata de un orden estatal justo expresado a través de una Constitución escrita, el reconocimiento de los derechos del hombre, la separación de poderes y garantizado por leyes producidas y promulgadas conforme procedimientos debidamente establecidos.
} 
razão dos diversos acontecimentos históricos, é inequívoco que o próprio Estado de Direito também sofre mudanças, motivo pelo qual é possível constatar suas várias fases ao longo da História.

Logo quando surgiu, esse novo modelo estatal ficou conhecido também como "Estado Liberal". Sua proposta de limitação do poder estatal e de garantia dos direitos do homem possuiu viés essencialmente individualista. Os direitos civis e políticos foram colocados em pauta sob a diretriz dos interesses burgueses, tendencialmente voltados às liberdades individuais e ao direito de propriedade. Essa foi a concepção clássica do Estado de Direito.

Mais adiante, o Estado de Direito viveu uma nova fase, porquanto, em razão de diversos acontecimentos e circunstâncias sociais, passou a contemplar, no contexto do exercício da cidadania, não apenas os direitos civis e políticos, mas também os direitos sociais. De fato, tais direitos começaram a ser reconhecidos pelas ordens jurídicas estatais no período da revolução industrial, pois esse fenômeno acentuou a diferenciação entre as classes sociais e o avanço do regime democrático viabilizou o exercício de reivindicações e pressões políticas dialéticas (SCHÄFER, 2013, p. 48).

Assim, diante desse contexto, o Estado se viu impelido a exercer atividade diferente da que tradicionalmente desempenhava, evoluindo, conforme retrata Schäfer, "[...] de uma função inerte para uma postura promocional perante o cidadão" (2013, p. 48). O ideal de igualdade passou a nortear as reivindicações da população, conduzindo o Estado a assumir, principalmente após as consequências produzidas pela Segunda Guerra Mundial, uma responsabilidade social dentro da garantia do exercício pleno da cidadania. Foi nesse contexto, então, que se desenvolveu o Estado Social de Direito, também conhecido como Estado de Bem-estar Social, denominação dada por muitos à fase em que o Estado de Direito voltou-se, de maneira intensa, à proteção dos direitos sociais. 
Contemporaneamente, entende-se que o Estado de Direito vive sua terceira fase, intitulada "Estado Democrático de Direito". Essa fase é marcada por reflexões a respeito da legitimidade do poder. De fato, a proteção de direitos do homem em documentos jurídicos não impediu que surgissem regimes totalitários, os quais, na prática, acabaram desrespeitando boa parte desses direitos. Assim, a temática da legitimidade ganhou destaque no cenário político-jurídico do século $\mathrm{XX}$, a respeito da qual Habermas e Häberle (2003, p. 68) preconizam que:

É que o Direito não somente exige aceitação; não apenas solicita dos seus endereçados reconhecimento de fato, mas também pleiteia merecer reconhecimento. Para a legitimação de um ordenamento estatal, constituído na forma da lei, requerem-se, por isso, todas as fundamentações e construções públicas que resgatarão esse pleito como digno de ser reconhecido.

Desse modo, procurando conjugar as conquistas jurídicas alcançadas em fases anteriores, o Estado de Direito do século 20, isto é, o Estado Democrático de Direito, traz em seu cerne a preocupação com a efetividade das normas jurídicas a partir de um sistema consagrador de mecanismos democráticos de exercício do poder, em especial daqueles voltados ao exercício da soberania popular.

Diante dessa nova perspectiva, hoje o Brasil assume ser um Estado Democrático de Direito, fundamentando-se nas premissas inerentes ao exercício democrático do poder e procurando, no que diz respeito à proteção de direitos, conjugar em seu ordenamento jurídico as conquistas históricas alcançadas durante o período em que adotou a postura de um Estado Liberal e, posteriormente, de um Estado Social de Direito. 
Com efeito, a Constituição Federal brasileira reconhece o Brasil como um Estado Democrático de Direito, e conclama, como base do sistema jurídico do país, a realização da dignidade humana por intermédio da proteção aos direitos civis, políticos e sociais, os ditos direitos fundamentais.

Essa proteção norteia todo o sistema, e é com base nela que a temática da legitimidade e dos mecanismos democráticos do exercício do poder é trabalhada no ordenamento jurídico. Assim, vê-se que, ao passo que a democracia foi se desenvolvendo no Brasil, o Estado de Direito também o foi. Ocorre que esse modelo estatal não funciona de maneira plena e eficaz, e, nesse sentido, a grande questão que se levanta é justamente o impacto de suas inúmeras falhas na então conclamada democracia do país.

\subsection{A inefetividade dos direitos fundamentais no Brasil}

Conforme retratado anteriormente, a proteção dos direitos fundamentais constitui a base do sistema jurídico brasileiro, o qual tem como premissa fundamental assegurar o respeito à dignidade humana. Com efeito, na perspectiva da nova ordem constitucional contemporânea, pode-se afirmar que na maior parte dos sistemas jurídicos atuais a dignidade da pessoa humana e os direitos fundamentais formam a indispensável base constitucional antropológica que estrutura do Estado de Direito (CANOTILHO, 1997, p. 42).

Esse novo panorama jurídico foi estabelecido em razão das consequências devastadoras produzidas pela Segunda Guerra Mundial bem como da clara ausência de limitações jurídicas capazes de impedir ações desumanas provocadas por regimes autoritários. Assim, diante desse contexto, a proteção da dignidade humana foi conclamada como a nova diretriz das relações internacionais. 
Nesse sentido, além da criação da Organização das Nações Unidas, em 1945, foram elaborados diversos documentos jurídicos internacionais voltados à questão da garantia de uma vida digna. $\mathrm{O}$ primeiro desses documentos foi a Declaração Universal dos Direitos Humanos, proclamada em 1948. A partir de sua elaboração, a ONU, representando a maior parte dos países do globo, devolveu, como bem-retrata Sorto (2009, p. 20), “[...] o ser humano ao seu devido lugar, isto é, ao centro do processo normativo e protetor, dando-lhe a titularidade e a subjetividade no plano internacional”.

Desse modo, seguindo a linha do novo panorama jurídico internacional, e fazendo jus às conquistas nacionais alcançadas, principalmente após a ditadura militar, a Constituição Federal brasileira de 1988 destinou um título inteiro à proteção dos direitos e garantias fundamentais, inserindo nele não apenas os direitos civis e políticos, mas, também, de maneira inovadora, os direitos sociais. Essa nova postura do ordenamento jurídico brasileiro revela o esforço do sistema em acompanhar os avanços jurídicos do século 20 e, por conseguinte, a nova estrutura do Estado de Direito.

Assim, após ter passado pelas diversas fases históricas do Estado de Direito, conforme mencionado, o Brasil se reconhece, hoje, um Estado Democrático de Direito, firmando-se em um sistema jurídico que pressupõe a submissão de todos ao que é estabelecido democraticamente pelo direito posto na sociedade. Nessa perspectiva, entende-se que cabe a esse direito não apenas estabelecer limitações ao exercício do poder, mas também assegurar direitos fundamentais e viabilizar uma maior participação dos cidadãos na própria construção do regime.

Ocorre que, na prática, muitos dos direitos fundamentais constitucionalmente assegurados no país não são vividos de maneira efetiva pela população brasileira. É verdade que muito se conquistou desde a época da ditadura até os tempos atuais, em especial no que respeita à consagração dos direitos políticos e ao restabelecimento dos direitos civis. Boa parte da população do país, todavia, vive à margem do exercício pleno da cidadania. 
Nesse sentido, embora se entenda, hoje, que o exercício da cidadania envolve necessariamente a garantia efetiva dos direitos civis, políticos e sociais, bem como os deveres a ela relacionados, a inefetividade desses direitos continua presente no cenário nacional. Situações como a corrupção do sistema político do país, a insegurança social, a violência e a pobreza, ainda marcam a realidade brasileira e suscitam questionamentos acerca do reconhecido Estado de Direito do país.

A respeito da consagração dos direitos fundamentais na Constituição de muitos países e da controversa inefetividade desses direitos em termos práticos, Avelãs Nunes (2013, p. 182) destaca que:

Esta consagração significa, desde logo, que o povo soberano quer que aqueles direitos sejam tratados como direitos fundamentais e significa, por outro lado, que os órgãos do poder político democrático devem sentir-se política e juridicamente vinculados a atuar no sentido da sua efetiva concretização. Não se trata de enganar os povos com promessas ilusórias. Trata-se de ajudá-los a construir um futuro digno dos homens.

A ideia de um Estado de Direito, cujo conceito fora abordado em oportunidade anterior, envolve elementos que vão além da questão da proteção dos direitos fundamentais. É inequívoco, no entanto, que seu conceito passa necessariamente pela proteção desses direitos, pois ela representa um dos grandes mecanismos de limitação do poder estatal.

Sendo assim, questiona-se se, diante das inúmeras falhas na garantia dos direitos fundamentais à população do país, o sistema jurídico brasileiro pode ser considerado um autêntico Estado Democrático de Direito. Ora, se a própria base do sistema não funciona de maneira plena, é impossível considerar que esse sistema funciona em toda a sua plenitude.

E mais, se resta clara a fragilidade do suposto Estado de Direito brasileiro, resta evidente também a baixa qualidade da democracia do país, porquanto, como bem-retratam Mainwaring, Brinks e Perez-Liñán (2001, p. 659), o conceito de democracia não pode se restringir apenas ao ele- 
mento eleitoral do sistema, mas deve passar necessariamente por outras dimensões igualmente importantes, dentre as quais se destaca justamente a não violação dos direitos do ser humano.

\section{CONSIDERAÇÕES FINAIS}

De acordo com o que fora retratado no presente artigo, para Mainwaring, Brinks e Pérez-Liñán, o conceito procedural de democracia defendido por Schumpeter e seus seguidores se reduz a uma mera concepção submínima. Com efeito, segundo tais autores, embora a democracia envolva, impreterivelmente, a existência de eleições livres e justas para a escolha dos representantes políticos, sua definição abarca outras dimensões importantes além da eleitoral.

A sustentação, pelos referidos autores, de que um regime democrático deve possuir também a garantia de uma cidadania adulta e abrangente, a proteção das liberdades civis e dos direitos políticos, e a existência de poder de governo genuíno por parte das autoridades, leva à conclusão de que a vigência autêntica de um Estado de Direito é indispensável para ser possível a existência plena de uma democracia.

Há, entretanto, de se destacar que o conceito de Estado de Direito não é algo estanque. Para entendê-lo, é preciso compreender as circunstâncias históricas de seu surgimento e o desenvolvimento de suas diversas fases. Mesmo assim, não restam dúvidas de que sua essência conceitual passa necessariamente pela realidade de um sistema jurídico que estabelece a submissão igualitária de todos ao direito posto na sociedade, e que esse sistema deve envolver uma série de elementos importantes, a exemplo da existência de um texto constitucional e de normas protetoras dos direitos fundamentais do ser humano. 
Nesse sentido, conquanto seja evidente a evolução democrática do Brasil, as constantes situações de inefetividade dos direitos fundamentais no país demonstram que ainda existem graves falhas que enfraquecem o proclamado Estado Democrático brasileiro. Diante dessa realidade, não resta outro caminho a não ser questionar a qualidade da democracia no Brasil, a qual somente conseguirá funcionar de maneira plena se superar os desafios que a limitam.

\section{REFERÊNCIAS}

ALBUQUERQUE, Armando. Teoria democrática contemporânea: de Schumpeter a Mainwaring. In: NOVELINO, Marcelo; ALMEIDA FILHO, Agassi (Org.). Leituras complementares de direito constitucional: teoria do Estado. Salvador: JusPODIVM, 2009.

AVELÃS NUNES, A. J. O estado capitalista e suas máscaras. Rio de Janeiro: Lúmen Júris, 2013.

BOBBIO, Norberto. Três ensaios sobre a democracia. Tradução Sérgio Bath. São Paulo: Cardim-Alario, 1991.

A era dos direitos. Tradução Carlos Nelson Coutinho. Rio de Janeiro: Elsevier, 2004.

BORDA, Luis Villar. Estado de derecho y Estado social de derecho. Revista Derecho Del Estado, n. 20, p.73-96, dez. 2007.

CANOTILHO, J. J. Gomes. Direito constitucional e teoria da constituição. 3. ed. Coimbra: Livraria Almedina, 1997.

CARVALHO, José Murilo. Cidadania no Brasil: o longo caminho. 8. ed. Rio de Janeiro: Civilização Brasileira, 2006.

COSTA, Pietro. O estado de direito: uma introdução histórica. In: COSTA, Pietro; ZOLO, Danilo (Org.). O Estado de direito. Tradução Carlos Alberto Dastoli. São Paulo: Martins Fontes, 2006.

DAHL, Robert A. Sobre a democracia. Tradução Beatriz Sidou. Brasília: Universidade de Brasília, 2001. 
HABERMAS, J.; HÄBERLE, P. Sobre a legitimação pelos direitos humanos. In: MERLE, J.; MOREIRA, L. (Org.). Direito e legitimidade. São Paulo: Landy, 2003.

HUNTINGTON, Samuel P. The third wave: democratization in the late twentieth century. Oklahoma: University of Oklahoma Press, 1993.

MAINWARIG, Scott; BRINKS, Daniel; PÉREZ-LIÑÁN, Aníbal. Classificando regimes políticos na América Latina, 1945-1999. Revista de Ciências Sociais, Rio de Janeiro, vol. 44, n. 4, p. 645-687, 2001.

OLIVEIRA, Luzia Helena Herrmann. Processo democrático e visões da democracia no Brasil. Revista de Ciências Humanas, Florianópolis, n. 32, p. 399-437, 2002.

PAIXÃO, Cristiano. Direito, política, autoritarismo e democracia no Brasil: da Revolução de 30 à promulgação da Constituição da República de 1988. Araucaria: Revista Iberoamericana de Filosofia, Política y Humanidades, ano 13, n. 26, p. 146-169, 2011.

SARLET, Ingo Wolfgang. Os direitos fundamentais sociais na Constituição de 1988. Revista Diálogo Jurídico, Salvador, vol. I, n. 1, 2001.

SCHÄFER, Jairo. Classificação dos direitos fundamentais: do sistema geracional ao sistema unitário: uma proposta de compreensão. 2. ed. rev. atual. Porto Alegre: Livraria do Advogado, 2013.

SCHUMPETER, Joseph A. Capitalismo, socialismo e democracia. Tradução Ruy Jugmann. Rio de Janeiro: Fundo de Cultura, 1961.

SORTO, Fredys Orlando. Cidadania e nacionalidade: institutos jurídicos de Direito interno e de Direito internacional. Verba Juris: Anuário da Pós-Graduação em Direito, João Pessoa, ano 8, n. 8, p. 41-64, jan./dez. 2009.

Recebido em: 13/3/2016

Revisões requeridas em: 30/5/2016

Aprovado em: 19/8/2016 